\title{
Is conversion therapy possible in stage IV gastric cancer: the proposal of new biological categories of classification
}

\author{
Kazuhiro Yoshida $^{1} \cdot$ Kazuya Yamaguchi $^{1} \cdot$ Naoki Okumura $^{1} \cdot$ Toshiyuki Tanahashi $^{1}$. \\ Yasuhiro Kodera ${ }^{2}$
}

Received: 20 May 2015/Accepted: 6 November 2015/Published online: 7 December 2015

(c) The Author(s) 2015. This article is published with open access at Springerlink.com

\begin{abstract}
Conversion therapy for gastric cancer (GC) has been the subject of much recent attention. It is defined as a surgical treatment aiming at an $\mathrm{R} 0$ resection after chemotherapy for tumors that were originally unresectable or marginally resectable for technical and/or oncological reasons. However, the indications for resection remain to be clarified. In the present review, we focus on the biology and heterogeneous characteristics of stage IV GC and propose new categories of classification. Stage IV GC patients can be divided based on the absence (categories 1 and 2) or presence (categories 3 and 4) of macroscopically detectable peritoneal dissemination, which has a different biological outcome compared to hematological metastasis. Category 1 is defined oncologically as stage IV but the metastasis is technically resectable. Category 2 includes a marginally resectable metastasis or patients for whom the operation would not necessarily be the best choice. Category 3 includes a potentially unresectable metastasis of peritoneal dissemination that is only macroscopically detectable. Category 4 includes noncurable metastasis with peritoneal and other organ metastasis. The indications for conversion therapy might include the patients from category 2 , some patients from category 3 and a very small number of patients from category 4 . The longer survival can be expected for patients corresponding to categories 1,2 and, to a lesser extent, 3 , while the treatment of other patients
\end{abstract}

Kazuhiro Yoshida

kyoshida@gifu-u.ac.jp

1 Department of Surgical Oncology, Gifu University Graduate School of Medicine, 1-1 Yanagido, Gifu 501-1194, Japan

2 Department of Gastroenterological Surgery, Nagoya University Graduate School of Medicine, Nagoya, Japan focuses on "care." The provision of conversion therapy for stage IV GC patients might be one of the main roles of surgical oncologists in the near future.

Keywords Gastric cancer - Conversion therapy · Adjuvant surgery $\cdot$ Chemotherapy $\cdot$ Stage IV gastric cancer

\section{Introduction}

In spite of early diagnosis and improved intensive treatments, GC remains the second leading cause of death throughout the world [1]. With the development of therapeutic approaches, the standard treatment of GC has been established, as is demonstrated in the Japanese treatment guidelines for GC [2]. Treatments include ESD in T1a tumors, laparoscopic surgery or, to a lesser extent, lymphadenectomy in T1b tumors and standard D2 lymphadenectomy for locally advanced resectable gastric cancer. As for metastatic and recurrent GC, several new regimens have been developed that improve patient survival [3-7]. However, the median survival time (MST) remains at only $13-16$ months. In order to further improve the survival of stage IV GC patients, new therapeutic approaches should be considered [8,9].

On the other hand, recent improvements in the survival of metastatic colorectal cancer patients have mainly depended on new cytotoxic and molecular target agents (FOLFOX, FOLFIRI, XELOX and SOX with bevacizumab, cetuximab, panitumab, regorafinib and ramcirumab), which have recently achieved an increase in MST from 6 to 30 months [10-17]. Moreover, the surgical approach to metastatic lesions designated for conversion therapy or an oncosurgical approach has played a very crucial role in the prolonged survival of metastatic 
colorectal patients [18-20] because this operation, which aims at R0 resection, might be able to cure patients with metastatic lesions for whom the major treatment would previously have been chemotherapy.

Although the prognosis of stage IV GC has recently improved as the result of new chemotherapeutic and molecular targeting agents, it remains unsatisfactory. With the development and improved response of the chemotherapy regimens, a number of conversion therapy approaches have been successfully demonstrated in stage IV GC [21-26]. However, significant aspects of these approaches, such as the indications, chemotherapy regimens and timing of the operation, remain to be clarified. In the present review, current developments in the treatment of stage IV GC will be discussed, conversion therapy will be defined and new categories of classification for stage IV GC will be proposed.

\section{The history of metastatic GC clinical trials in Japan}

According to the updated Japanese guidelines on gastric cancer [27], S-1 plus cisplatin (S-1/CDDP) is regarded as the first-line chemotherapy and is the first-level recommendation in HER 2-negative patients. The capecitabine plus cisplatin (XP) regimen and S-1 plus docetaxel (S-1/docetaxel) are also nominated as the second-level recommendations. On the other hand, in HER 2-positive patients, trastuzumab $+\mathrm{XP}$ is regarded as the recommended treatment regimen [7]. This consensus has been established on the basis of the history of clinical trials (Fig. 1), and the results of trials in Japan are summarized in Table 1. Trials in Western countries are also summarized in Table 2.

JCOG9912 [28] was the first pivotal trial to compare $5 \mathrm{FU}$ versus $\mathrm{S}-1$ versus CPT11 plus cisplatin (CPT/CDDP) in Japan; however, it did not demonstrate the superiority of CPT/CDDP. As a result, S-1 was regarded as the standard regimen. S-1/CDDP was compared to S-1 monotherapy in the SPIRITS trial [3], which demonstrated the combination of cisplatin ( $60 \mathrm{mg} / \mathrm{m}^{2}$ for 8 days) with S-1 for 3 weeks on and 2-weeks off. The treatment was repeated every 5 weeks, unless disease progression was observed. The MST for S-1/CDDP and S-1 was 13.0 and 11.0 months, respectively, and the superiority of $S-1 / C D D P$ was demonstrated. A randomized phase III trial (TOP 002) was conducted to evaluate the safety and efficacy of IRIS (S-1/ CPT-11) versus S-1 for advanced gastric cancer, which could not demonstrate a significant difference in patient survival [29]. The START trial was a randomized phase III study comparing S-1 alone with the S-1/docetaxel combination through the JACCRO GC03 trial [5]. This study was a prospective, multicenter, multinational (Korea and Japan), randomized, phase III study of patients with AGC. Docetaxel $\left(40 \mathrm{mg} / \mathrm{m}^{2}\right.$ on day 1) was administered with S-1 $\left(80 \mathrm{mg} / \mathrm{m}^{2} /\right.$ day) for 2 weeks on and 1 week off. The MST for S-1/docetaxel and S-1 was 12.5 and 10.8 months, respectively, and the HR was 0.837 (95\% CI 0.711-0.985; $P=0.0319$ ), showing the significant superiority of the doublet regimen. Moreover, in the patients with non-measurable lesions, MST for S-1/docetaxel and S-1 was 17.9 and 12.0 months, respectively. A prospective randomized control trial of adjuvant therapy for stage III GC is currently being conducted to compare S-1/docetaxel versus S-1 monotherapy as a control arm. On the other hand, as a modification of the 5-weekly S-1/CDDP regimen, the SOS trial demonstrated that the triweekly S-1/CDDP regimen has the same efficacy as the original schedule. In order to reduce the renal toxicity, oxaliplatin was used to replace cisplatin [30]. The G-SOX trial demonstrated an equal efficacy with lower toxicity and will be widely administered in general practice [31]. In the SOX regimen, oxaliplatin $\left(100 \mathrm{mg} / \mathrm{m}^{2}\right.$ on day 1$)$ was administered with $\mathrm{S}-1$ $\left(80 \mathrm{mg} / \mathrm{m}^{2} /\right.$ day) for the first 2 weeks of a 3-week cycle.

The Trastuzumab for Gastric Cancer (ToGA) Study [7], a phase III trial of trastuzumab combined with standard chemotherapy, previously demonstrated an MST of 13.8 months for the trastuzumab plus chemotherapy arm compared to 11.1 months for the chemotherapy-alone arm $(P=0.0046)$ and showed significant improvements in time-to-progression (TTP) and progression-free survival (PFS) in the trastuzumab-treated group with a comparable
Fig. 1 The history of metastatic GC clinical trials in Japan

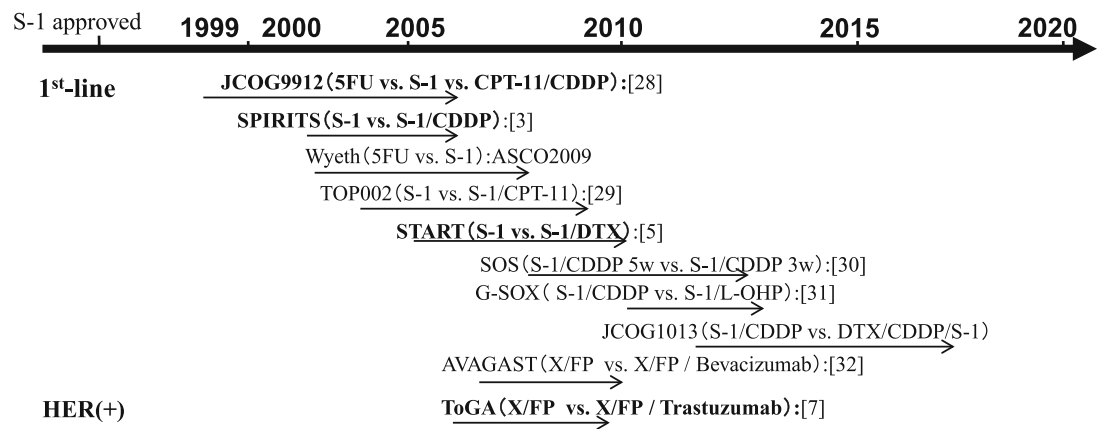


Table 1 Involvement of non-measurable lesions in Japanese clinical trials

\begin{tabular}{|c|c|c|c|c|c|c|c|}
\hline \multirow[t]{2}{*}{ Trial [Ref no.] } & \multirow[t]{2}{*}{ Treatment } & \multirow{2}{*}{$\begin{array}{l}\text { Response } \\
\text { rate }(\%)\end{array}$} & \multicolumn{3}{|c|}{ Median overall survival $(M)$} & \multicolumn{2}{|c|}{ Frequency of non-measurable lesions } \\
\hline & & & Total population & Measurable & Non-measurable & $(\%)$ & Total \\
\hline \multirow[t]{3}{*}{ JCO9912 [28] } & $5-\mathrm{FU}$ & 9 & 10.8 & N/A & N/A & $37.2 \%(87 / 234)$ & $33.0 \%(232 / 704)$ \\
\hline & CPT-CDDP & 38 & 12.3 & & & $32.2 \%(76 / 236)$ & \\
\hline & $\mathrm{S}-1$ & 28 & 11.4 & & & $29.4 \%(69 / 234)$ & \\
\hline \multirow[t]{2}{*}{ SPIRITS [3] } & S-1 & 31 & 11.0 & N/A & N/A & $24 \%(36 / 150)$ & $29.2 \%(87 / 298)$ \\
\hline & S-1/CDDP & 54 & 13.0 & & & $34 \%(51 / 148)$ & \\
\hline \multirow[t]{2}{*}{ TOP-002 [29] } & S-1 & 26.9 & 10.5 & N/A & N/A & N/A & $33.3 \%(105 / 315)$ \\
\hline & $\mathrm{S}-1 / \mathrm{CPT}$ & 41.5 & 12.8 & & & N/A & \\
\hline \multirow[t]{2}{*}{ START [5] } & S-1 & 26.8 & 10.8 & 10.3 & 12.0 & $40.8 \%(131 / 321)$ & $39.3 \%(250 / 635$ \\
\hline & S-1/DTX & 38.8 & 12.5 & 11.7 & 17.9 & $37.9 \%(119 / 314)$ & \\
\hline \multirow[t]{2}{*}{ SOS [30] } & SP5 & 50 & 13.9 & N/A & N/A & $37 \%(113 / 309)$ & N/A \\
\hline & SP3 & 60 & 14.1 & & & $39 \%(120 / 306)$ & \\
\hline \multirow[t]{2}{*}{ G-SOX [31] } & SP & 52.2 & 13.1 & N/A & N/A & $19.8 \%(64 / 324)$ & $19.5 \%(125 / 642)$ \\
\hline & SOX & 55.7 & 14.1 & & & $19.2 \%(25 / 294)$ & \\
\hline \multirow[t]{2}{*}{ ToGA [7] } & $\mathrm{XP}$ & 35 & 11.1 & N/A & N/A & $11.3 \%(33 / 290)$ & $9.9 \%(58 / 584)$ \\
\hline & $\mathrm{XP}+\mathrm{Tmab}$ & 47 & 13.8 & & & $8.5 \%(25 / 294)$ & \\
\hline \multirow[t]{2}{*}{ AVAGAST [32] } & $\mathrm{XP}$ & 37.4 & 10.1 & N/A & N/A & $23.2 \%(90 / 387)$ & $21.4 \%(166 / 774)$ \\
\hline & $\mathrm{XP}+\mathrm{Bev}$ & 46.0 & 12.1 & & & $19.6 \%(76 / 387)$ & \\
\hline
\end{tabular}

Table 2 Involvement of non-measurable lesions clinical trials of Western countries

\begin{tabular}{|c|c|c|c|c|c|c|c|}
\hline \multirow[t]{2}{*}{ Trial [Ref no.] } & \multirow[t]{2}{*}{ Treatment } & \multirow[t]{2}{*}{ Response rate $(\%)$} & \multicolumn{3}{|c|}{ Median overall survival $(M)$} & \multicolumn{2}{|c|}{ Frequency of non-measurable lesions } \\
\hline & & & Total population & Measurable & Non-measurable & $(\%)$ & Total \\
\hline \multirow[t]{3}{*}{ EORTC [37] } & FAMTX & 12 & 6.7 & N/A & N/A & $12.3 \%(16 / 130)$ & $12.8 \%(50 / 390)$ \\
\hline & ELF & 9 & 7.2 & & & $14.8 \%(19 / 128)$ & \\
\hline & FUP & 20 & 7.2 & & & $11.4 \%(15 / 132)$ & \\
\hline \multirow[t]{2}{*}{ FLAGS [38] } & $\mathrm{CF}$ & 31.9 & 7.9 & N/A & N/A & $4.3 \%(22 / 508)$ & $4.2 \%(43 / 1029)$ \\
\hline & $\mathrm{CS}$ & 29.1 & 8.6 & & & $4.0 \%(21 / 521)$ & \\
\hline \multirow[t]{2}{*}{ V325 [39] } & $\mathrm{CF}$ & 25 & 8.6 & N/A & N/A & N/A & N/A \\
\hline & DCF & 37 & 9.2 & & & N/A & \\
\hline \multirow[t]{2}{*}{ CF versus IF [40] } & $\mathrm{CF}$ & 25.8 & 8.7 & N/A & N/A & $25.2 \%(41 / 163)$ & $24.3 \%(81 / 333)$ \\
\hline & IF & 31.8 & 9.0 & & & $23.5 \%(40 / 170)$ & \\
\hline \multirow[t]{4}{*}{ REAL-2 [41] } & ECF & 40.7 & 9.9 & N/A & N/A & N/A & N/A \\
\hline & ECX & 46.4 & 9.9 & & & N/A & \\
\hline & EOF & 42.4 & 9.3 & & & N/A & \\
\hline & EOX & 47.9 & 11.2 & & & N/A & \\
\hline \multirow[t]{2}{*}{ ML17032 [42] } & FP & 32 & 9.3 & N/A & N/A & $18.6 \%(29 / 156)$ & $18.7 \%(59 / 316)$ \\
\hline & $\mathrm{XP}$ & 46 & 10.5 & & & $18.8 \%(30 / 160)$ & \\
\hline
\end{tabular}

toxicity profile. Capecitabine/5-FU and CDDP were the control arm schedule. The MSTs of XP in Japanese patients in the AVAGAST [32] and ToGA subset analysis [33] were 14.2 and 17.7 months, respectively. XP plus trastuzumab is regarded as the standard regimen in HER 2-positive patients as the first-level recommendation, and $\mathrm{XP}$ in HER 2-negative patients is the second-level recommendation.

More recently, DCS (Docetaxel/CDDP/S-1) therapy [34, 35] has been considered to be more effective and is 
currently being compared to S-1/CDDP in an ongoing randomized trial. Recent clinical trials have shown improved results in the treatment of stage IV gastric cancer. However, MST of stage IV GC remains from 3 to 4 months of best supportive care [36] to 17 months at most, which is summarized in Tables 1 and 2 [37-43], as explained above. Concerning the patients with non-measurable lesions including peritoneal disease, ascites, pleural effusion and minimal residual cancers, there can be a general tendency of longer survival compared to patients with measurable lesions according to subset analysis in most of the clinical trials. Tables 1 and 2 demonstrate the involvement of nonmeasurable lesions in the pivotal clinical trials in Japan and Western countries, respectively. In the START trial [5], as mentioned above, MST of S-1/docetaxel in non-measurable lesions was $17.9 \mathrm{M}$ and that of $\mathrm{S}-1$ alone was $12.0 \mathrm{M}$. Interestingly, MST of measurable lesions was not different between the two arms. Similar results were observed in the SPIRITS trial [3], which is regarded as the standard treatment in Japan, and more patients with non-measurable lesions were enrolled in the S-1/CDDP treatment group compared to the S-1 alone group in this study.

\section{Surgical intervention for stage IV GC}

Gastric bypass, jejunojejunostomy, ileostomy and colostomy are sometimes performed for pylorus stenosis of the primary tumor and/or tumors of peritoneal disseminated disease in cases of unresectable GC. As is clarified in the Japanese guidelines, in many cases, even if an $\mathrm{R} 0$ resection cannot be achieved, the primary tumors are removed in palliative operations to correct bleeding and/or obstruction of the stomach and bowels [44-47]. In the case of pylorus stenosis, an expanding stent is now available [48]. The techniques for the use of the expanding stent have already been established and are becoming prevalent; however, they sometimes cause bleeding or dislocation. Recently, instead of using a bypass operation or metallic stenting, enteral nutritional management has often been performed, using a feeding tube over a pylorus ring in order to enhance nutrition and improve chemotherapy compliance as well as to administer oral fluoropyrimidine chemotherapy [49].

With regard to the palliative resection of the primary tumor, the REGATTA trial demonstrated that the initial removal of the primary tumor is not necessarily beneficial [50]. The indications for primary tumor resection in the trial were for stage IV GC patients who have only one affected organ other than the site of the primary tumor, such as peritoneal disease, several liver metastases or a paraaortic lymph node (LN) including 16a1 and 16b2.

According to the Japanese guidelines, the main strategy for the treatment of stage IV GC is palliative chemotherapy
[2]. While the MST of stage IV GC has already been improved with the development of new chemotherapy regimens, it remains unsatisfactory. As mentioned above, we have previously demonstrated that the operative resection of the primary and/or metastatic lesions after successful chemotherapy can improve patient survival [21, 22]. Moreover, the survival of the patients with liver and/or lymph node metastasis had a better tendency compared to that with peritoneal dissemination [22]. Satoh et al. [23] demonstrated the feasibility of this approach with S-1 plus cisplatin, and Han et al. [24] demonstrated the survival benefit on curative resection in good responders to induction chemotherapy for patients with distant metastasis as well as peritoneal dissemination as reported by Okabe et al. [25]. However the patients who are eligible for such a procedure and the definition of the concept of "conversion therapy" remain to be clarified. The concept is currently the subject of confusion with regard to GC, because stage IV GC consists of heterogeneous conditions with a mixture of distant hematologic metastasis, distant LN metastasis and peritoneal dissemination. In the next section, we clarify the definitions of conversion therapy and suggest new categories of classification for stage IV GC based on oncosurgical treatment strategies.

\section{The new biological categories for the classification of stage IV GC}

Figure 2 demonstrates the new biological categories for the classification of stage IV GC. We have divided this population into four categories. Initially, stage IV GC can be divided into two categories depending on the absence or presence of macroscopic peritoneal dissemination, which has a different biological outcome compared to hematological metastasis (by CT scan, PET-CT, barium enema, CT colonography, laparotomy or staging laparoscopy) [51, 52]. In the end, peritoneal dissemination causes the obstruction of bowels or malignant ascites, often leading to mechanical ileus and/or cachexia. However, the patients with hematologic metastasis such as liver, lung and other organs often die from organ failure. Moreover, it is quite difficult to remove the peritoneal dissemination completely because theoretically it is disseminated in whole abdominal cavity. On the other hand, measureable lesions in the organ deposit can be removed surgically if technically feasible. Patients without macroscopic peritoneal dissemination are further divided into category 1 (potentially resectable metastasis) and category 2 (marginally resectable metastasis) [53]. Patients who have macroscopic peritoneal dissemination are divided into category 3 (incurable and unresectable except certain circumstances of local palliation needs) and category 4 (noncurable 


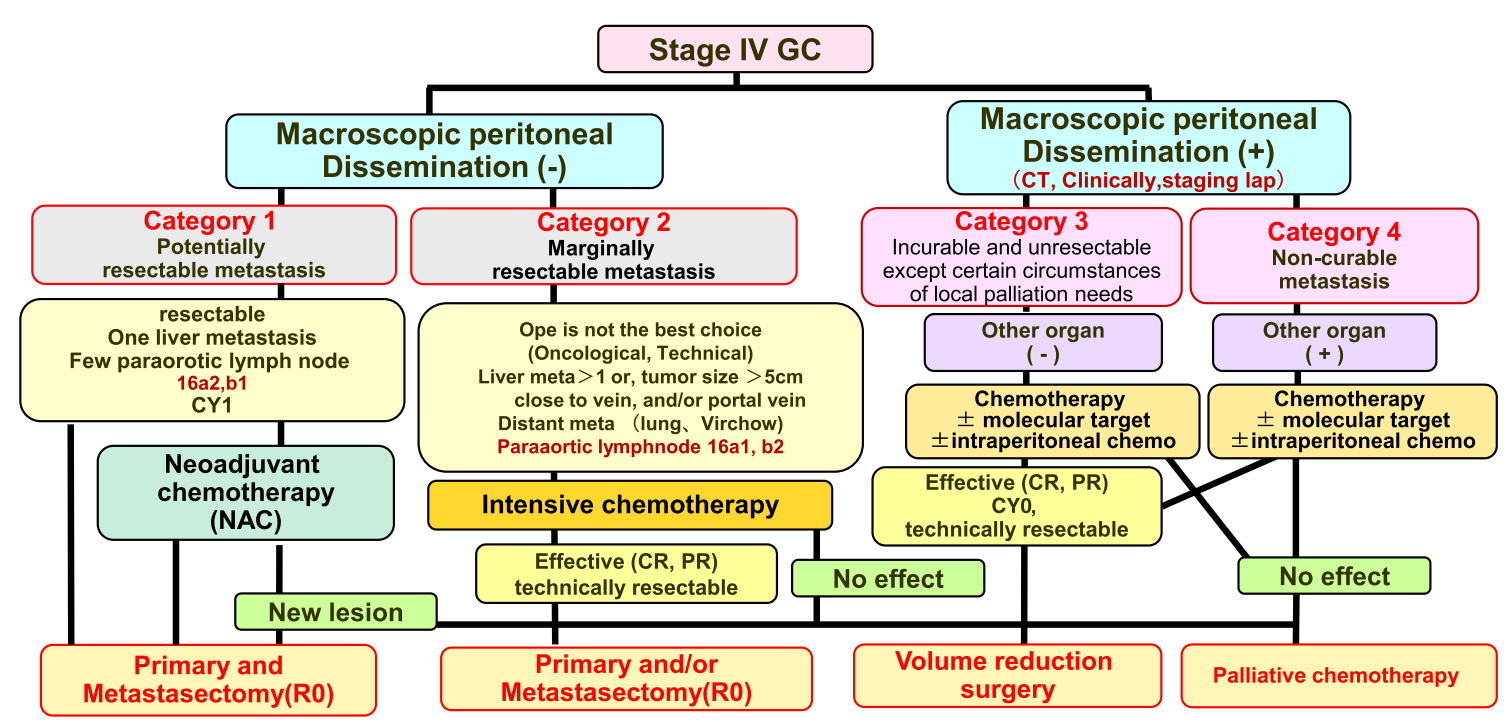

Fig. 2 The new biological categories for the classification of stage IV GC

metastasis). The patients with peritoneal disseminated disease diagnosed at the time of laparotomy or staging laparoscopy can be classified as category 3 , even if they were not diagnosed by the routine diagnostic tools. Essentially all patients with peritoneal carcinomatosis from $\mathrm{GC}$ are not curable, irrespective of the pretreatment extent or the ability to achieve an R0 resection, but survival outcomes differ based on the degree of disease advancement and extent in addition to therapy response. The longer survival can be expected for patients corresponding to categories 1, 2 and, to a lesser extent, 3 , while the treatment of other patients focuses on "care."

This classification also address "whom can I operate on without induction chemotherapy" or "whom can I operate on after chemotherapy." The concept of conversion therapy principally includes category 2 , some category 3 patients and rarely category 4 patients when the operations are performed with the goal of an R0 resection or a surgical cure [18-20, 54].

\section{a) Category 1: Potentially resectable metastasis}

This category includes patients with a single liver metastasis, with positive cytology or metastasis of the paraaortic LNs of no. $16 \mathrm{a} 2 \mathrm{and} /$ or $16 \mathrm{~b} 1$. This category is regarded as an oncologically stage IV but technically resectable metastasis.

Regarding the cytologically positive GC patients, Kodera et al. [55] demonstrated that the 5-year survival of patients after gastrectomy without macroscopic peritoneal disease but with cytologically positive metastasis (only) is more than $20 \%$. This markedly improved survival was probably due to the S-1 adjuvant treatment. Moreover, the prognosis of patients with $\mathrm{P} 0 \mathrm{CY} 1$ with R0 operation after chemotherapy is not yet known. Patients who were found P0 but CY1 can be included in this category. Whether such patients should be included in this category or another should be discussed with the accumulation of further cohort studies. As for liver metastasis, the survival of patients with a solitary liver metastasis was better than for patients with multiple metastases, suggesting the possible benefit of a metastasectomy at the time of primary tumor resection of the stomach [56-59]. Regarding paraaortic LN No. $16 \mathrm{a} 2$ and $16 \mathrm{~b} 1$ metastasis, patients with these technically resectable metastases have rather good prognoses after treatment with neoadjuvant chemotherapy (NAC) with S-1/CDDP therapy according to the JCOG study [60-64]. Moreover, these cases were excluded from the REGATTA trial. The above-mentioned cases are considered to represent technically resectable metastasis; hence, primary tumor resection and metastasectomy can be considered with or without NAC. The term NAC is used to describe intensive chemotherapy in patients with tumors that are technically resectable [65-69]. Resection after successful chemotherapy, which achieves a range of responses [complete response (CR), partial response (PR) or even stable disease (SD)], may lead to better expected survival in this category in comparison to patients who are treated with chemotherapy alone. In patients in whom a new lesion occurs after NAC, palliative chemotherapy will be continued. In this category, patients can be treated with either an operation before chemotherapy or an operation after NAC irrespective of the response to the chemotherapy.

\section{b) Category 2: Marginally resectable metastasis}

This category includes patients for whom the operation would not be considered to be the best choice for the initial 
treatment because of the presence of metastatic regions regarded as oncologically or technically unresectable. Regarding hepatic metastasis, patients with more than two liver metastases, a tumor size $>5 \mathrm{~cm}$ or a tumor that is close to the hepatic and/or portal vein might be included in this category [50]. As for LN metastasis, paraaortic LN No. 16a1, 16b2 and distant LN metastasis, including the mediastinal, supraclavicular, axillary lymph nodes and distant organ metastasis, might also be included in this category. The patients in category 2 would be treated with first-line chemotherapy as the induction chemotherapy because it might achieve a good response in the regions targeted for resection and primary tumor resection might be performed when distant metastatic lesions are regarded as showing clinically complete response. There are patients with isolated distant metastases that turn out to be resectable. In this situation, most oncologists may treat the patient with chemotherapy, confirming that the tumor can respond to it or not, and/or at least no new lesions appear before resection, because this biological situation is accepted as generalized disease.

Conversion therapy can be defined as the surgical treatment (aiming at R0 resection) after chemotherapy of tumors that were originally regarded as technically or oncologically unresectable or only marginally resectable. The concept of the operation can be defined as conversion surgery or adjuvant surgery. Chemotherapy should be continued for as long as possible after removal of the tumors until the tumors acquire resistance to chemotherapy or until uncontrollable adverse events occur in the patients.

\section{c) Category 3: Incurable and unresectable except certain circumstances of local palliation needs}

This category includes patients with only peritoneal disseminated disease detected by clinical routine examination as listed above, staging laparoscopy or at the time of initial open laparotomy. Recent chemotherapy can sometimes achieve the shrinking of bulky masses or peritoneal disseminated disease in the abdominal cavity [70]; however, it is quite rare for chemotherapy to extinguish all of the microscopic metastases, even after a satisfactory initial response, regardless of the presence or absence of metastasis in other organs [71-73]. When the metastatic site shows a good response to chemotherapy, primary tumors and/or metastatic tumors can be removed in the clinical setting after a staging laparoscopy confirming the CY0 and P0 situation. These operations can be defined as cytoreductive surgery or volume-reduction surgery even if a complete resection is performed because most of these cases recur afterwards in the peritoneal cavity [74]. Of course, this volume-reduction surgery can be partly included in the definition of conversion therapy. However, its clinical benefit should be clarified in the future.

In case of macroscopic peritoneal metastasis, even a single metastasis, limited to the lesser or greater omentum, this lesion might be included in this category. The lesion can be regarded as technically resectable but oncologically not.

\section{d) Category 4: Noncurable metastasis}

Most of the GC patients with macroscopic peritoneal dissemination and other organ metastasis are regarded as unresectable or never resectable. Conversion therapy could only be considered in a small fraction of patients in whom exceptional response to the first-line chemotherapy rendered R0 resection possible. Otherwise, patients should continue to receive palliative chemotherapy. Of course, there can be some cases of the primary tumor resection in palliative operations to cope with bleeding and/or obstruction of the stomach and bowels with the option of a bypass operation.

\section{Discussion}

We have previously demonstrated that surgical oncologists play a major role in conversion therapy or adjuvant surgery with chemotherapy regimens to further improve the prognosis of stage IV GC [21]. As reported elsewhere, this concept has recently received a great deal of attention. However, the definition of conversion therapy and the indications for operations remain to be clarified and, in the case of GC, are associated with a great deal of confusion. The reason for this is that previous reports included patients with GC who corresponded oncologically to stage IV but in whom metastasis was technically resectable. It has been previously demonstrated that such patients can be estimated to have better survival than patients with other metastatic lesions. Moreover, patients with peritoneal metastasis were also included in previous studies in which primary tumors were resected as cytoreductive surgery after successful induction chemotherapy. Long-term survival cannot be expected in such patients. Under these circumstances, it is not possible to clarify a significant role for conversion therapy.

In the present review, in order to better understand the biology and indications of curative surgery as a conversion therapy, we have proposed new categories for the classification of stage IV GC, taking into account the heterogeneous situation and treatment trends in general practice. In the new categories of classification, we have defined a potentially resectable metastasis as category 1 , which can be resected technically but is oncologically considered 
stage IV. Such tumors can be technically resectable at the initial diagnosis and can be resected irrespective of their response to NAC unless new lesions appear. Such treatment is not considered to be "conversion therapy."

The term "conversion therapy" describes a therapeutic concept in which the treatment strategy is converted by chemotherapy to curative surgery through an oncosurgical approach $[21,22,75,76]$. The terms "conversion surgery" or "adjuvant surgery" can be applied to the operations performed for conversion therapy. Salvage surgery describes surgery performed to remove residual tumors or regrown tumors after curative radiation or chemoradiation therapy in cases where the tumor has invaded the adjacent organs, as is described in the Japanese guidelines for the treatment of esophageal cancer [77, 78]. The main difference is that salvage surgery is conducted in locally advanced tumors but conversion therapy is conducted in patients with metastatic lesions as well as primary tumor.

In the 1980s, the resection of primary tumors or the removal of metastatic disease was often conducted in the course of volume-reduction surgery. However, the prognosis of patients who underwent volume-reduction surgery was not considered to be satisfactory because the response rate to chemotherapy in those days was around 20-30\% [39]. It is only recently that the complete removal of tumors has been found frequently to be possible after successful treatment with S-1 based chemotherapy regimens. Recently, the REGATTA trial demonstrated that palliative surgery followed by chemotherapy in stage IV $\mathrm{GC}$ is not beneficial to categories 2 and 3 patients and that chemotherapy should be performed before primary tumor resection [50]. As we have demonstrated previously, there are two reasons for this: chemotherapy compliance tends to be better before gastrectomy, and the increased level of cytokines after surgery may enhance the proliferation of tumors [79, 80].

As mentioned above, the indications for conversion therapy include category 2 patients, some category 3 patients and category 4 patients in whom an R0 resection can be expected after a satisfactory response to chemotherapy. Primary tumor resections with an adequate $\mathrm{LN}$ dissection can be performed in cases when other distant metastases (such as peritoneal dissemination or distant lymph node, liver or lung metastases) are absent or when they respond completely to chemotherapy and when the complete removal of liver deposits is feasible (at a macroscopic level) and, moreover, when the minimal residual tumors in distant $\mathrm{LN}$ metastasis after chemotherapy can be extensively removed. Several issues should be discussed in order to clarify this concept, including the timing of the operation, whether R0 operations are required, the best treatment regimen and whether chemotherapy is required after an R0 operation.
The best timing for the operation is generally when the tumor displays the best response to chemotherapy (not when the tumor is increasing in size or when it has acquired the ability to regrow). This has been demonstrated elsewhere in GIST treatment [81, 82]. Generally, we estimate the best timing for the removal of the tumor to be when a $\mathrm{CR}$ or $\mathrm{PR}$ response is detected during the performance of 4-6 cycles of S-1/CDDP or S-1/docetaxel regimens. However, as Yoshikawa et al. [83] reported recently, in the case of NAC, two cycles might be sufficient. Of course, the continuation of chemotherapy after such surgery might be required until the tumor acquires resistance to chemotherapy or uncontrollable adverse events occur, even after R0 resections [21, 84-86].

In conclusion, the administration of conversion therapy for stage IV GC cases might be one of the main roles of the surgical oncologist in the near future. This is a new therapeutic concept that warrants clinical evaluation by a prospective cohort study and/or randomized control trial. We are now conducting a prospective cohort study in order to estimate the feasibility of this concept (UMIN-ID: 000004787, https://upload.umin.ac.jp/cgi-open-bin/ctr/ctr. cgi?function=search\&action=input). Moreover, large-scale retrospective and prospective cohort studies are currently being conducted in Asia through the Federation of Asian Clinical Oncology (FACO), which consists of the Japanese Society of Clinical Oncology (JSCO), Korean Association of Clinical Oncology (KACO) and Chinese Society of Clinical Oncology (CSCO), with the support of the Japanese Gastric Cancer Association (JGCA), Korean Gastric Cancer Association (KGCA) and Gastric Cancer Association of the Chinese Anti-cancer Association.

Acknowledgments Authors acknowledge Mss. Aki Iwata, Kumi Mori, Kaori Enya and Kimiko Takano for their assistance with the preparation of the manuscript. This work was supported in part by Grants-in-Aid from the Japan Society of the Promotion of Science and from the Ministry of Health, Labour and Welfare of Japan.

\section{Compliance with ethical standards}

Conflict of interest K. Yoshida has received grants, personal fees and nonfinancial support from Chugai Pharmaceutical Co., Ltd., during the conduct of the study; grants and personal fees from Taiho Pharmaceutical Co., Ltd.; grants and personal fees from Pfizer Inc.; grants and personal fees from Chugai Pharmaceutical Co., Ltd.; grants and personal fees from Yakult Honsha Co., Ltd.; grants from BristolMyers Squibb; grants from Kyowa Hakko Kirin Co., Ltd., outside the submitted work; honoraria from Taiho Pharmaceutical Co., Ltd.; Pfizer Inc.; Chugai Pharmaceutical Co., Ltd.; Kyowa Hakko Kirin Co., Ltd.; Yakult Honsha Co., Ltd.; and had a consultant or advisory relationship to Taiho Pharmaceutical Co., Ltd., and La Roche, Ltd. Y. Kodera has received grants and personal fees from Chugai Pharmaceutical Co., Ltd.; Taiho Pharmaceutical Co., Ltd.; Sanofi Aventis; Bristol Myers Squib; Merck; Yakult Honsha Co., Ltd.; Daiichi Sankyo; Takeda Pharmaceutical Co., Ltd.; Eli Lilly Japan; and Pfizer; grants from AstraZeneca; and honoraria from Chugai Pharmaceutical 
Co., Ltd.; Taiho Pharmaceutical Co., Ltd.; Sanofi Aventis; and Takeda Pharmaceutical Co., Ltd., outside the submitted work. All remaining authors declared that they have no conflict of interest.

Open Access This article is distributed under the terms of the Creative Commons Attribution 4.0 International License (http://crea tivecommons.org/licenses/by/4.0/), which permits unrestricted use, distribution, and reproduction in any medium, provided you give appropriate credit to the original author(s) and the source, provide a link to the Creative Commons license, and indicate if changes were made.

\section{References}

1. GLOBOCAN 2012 database GLOBOCAN database. http://wwwdep.jarc.fr/globocan/globocan.html.

2. Sano T, Aiko T. New Japanese classifications and treatment guidelines for gastric cancer: revision concepts and major revised points. Gastric Cancer. 2011;14:97-100.

3. Koizumi W, Narahara H, Hara T, Takagane A, Akiya T, Takagi $\mathrm{M}$, et al. S-1 plus cisplatin versus S-1 alone for first-line treatment of advanced gastric cancer (SPIRITS trial): a phase III trial. Lancet Oncol. 2008;3:215-21.

4. Yoshida K, Ninomiya M, Takakura N, Hirabayashi N, Takiyama W, Sato Y, et al. Phase II study of docetaxel and S-1 combination therapy for advanced or recurrent gastric cancer. Clin Cancer Res. 2006;12:3402-7.

5. Koizumi W, Kim YH, Fujii M, Kim HK, Imamura H, Lee KH, et al. Addition of docetaxel to S-1 without platinum prolongs survival of patients with advanced gastric cancer: a randomized study (START). J Cancer Res Clin Oncol. 2014;140:319-28.

6. Tanabe K, Suzuki T, Tokumoto N, Yamamoto H, Yoshida K, Ohdan H. Combination therapy with docetaxel and S-1 as a firstline treatment in patients with advanced or recurrent gastric cancer: a retrospective analysis. World J Surg Oncol. 2010;8:40.

7. Bang Y, Van Cutsem E, Feyereislova A, Chung HC, Shen L, Sawaki A, et al. Trastuzumab in combination with chemotherapy versus chemotherapy alone for treatment of HER2-positive advanced gastric or gastro-oesophageal junction cancer (ToGA): a phase 3, open-label, randomised controlled trial. Lancet. 2010;376:687-97.

8. Shen L, Shan YS, Hu HM, Price TJ, Sirohi B, Yeh KH, et al. Management of gastric cancer in Asia: resource-stratified guidelines. Lancet Oncol. 2013;14:e535-47.

9. Lordick F, Siewert J. Recent advances in multimodal treatment for gastric cancer: a review. Gastric Cancer. 2005;8:78-85.

10. Taieb J, Tabernero J, Mini E, Subtil F, Folprecht G, Van Laethem $\mathrm{JL}$, et al. Oxaliplatin, fluorouracil, and leucovorin with or without cetuximab in patients with resected stage III colon cancer (PETACC-8): an open-label, randomised phase 3 trial. Lancet Oncol. 2014;15:862-73.

11. Heinemann V, von Weikersthal LF, Decker T, Kiani A, VehlingKaiser U, Al-Batran SE, et al. FOLFIRI plus cetuximab versus FOLFIRI plus bevacizumab as first-line treatment for patients with metastatic colorectal cancer (FIRE-3): a randomised, openlabel, phase 3 trial. Lancet Oncol. 2014;15:1065-75.

12. Cassidy J, Tabernero J, Twelves C, Brunet R, Butts C, Conroy T, et al. XELOX (capecitabine plus oxaliplatin): active first-line therapy for patients with metastatic colorectal cancer. J Clin Oncol. 2004;22:2084-91.

13. Yamada Y, Takahari D, Matsumoto H, Baba H, Nakamura M, Yoshida K, et al. Leucovorin, fluorouracil, and oxaliplatin plus bevacizumab versus $\mathrm{S}-1$ and oxaliplatin plus bevacizumab in patients with metastatic colorectal cancer (SOFT): an open-label, non-inferiority, randomised phase 3 trial. Lancet Oncol. 2013;14:1278-86.

14. Wasan H, Meade AM, Adams R, Wilson R, Pugh C, Fisher D, et al. Intermittent chemotherapy plus either intermittent or continuous cetuximab for first-line treatment of patients with KRAS wild-type advanced colorectal cancer (COIN-B): a randomised phase 2 trial. Lancet Oncol. 2014;15:631-9.

15. Schwartzberg LS, Rivera F, Karthaus M, Fasola G, Canon JL, Hecht JR, et al. PEAK: a randomized, multicenter phase II study of panitumumab plus modified fluorouracil, leucovorin, and oxaliplatin (mFOLFOX6) or bevacizumab plus mFOLFOX6 in patients with previously untreated, unresectable, wild-type KRAS exon 2 metastatic colorectal cancer. J Clin Oncol. 2014;32:2240-7.

16. Grothey A, Van Cutsem E, Sobrero A, Siena S, Falcone A, Ychou $\mathrm{M}$, et al. Regorafenib monotherapy for previously treated metastatic colorectal cancer (CORRECT): an international, multicentre, randomised, placebo-controlled, phase 3 trial. Lancet. 2013;381:303-12.

17. Garcia-Carbonero R, Rivera F, Maurel J, Ayoub JP, Moore MJ, Cervantes A, et al. An open-label phase II study evaluating the safety and efficacy of ramucirumab combined with mFOLFOX-6 as first-line therapy for metastatic colorectal cancer. Oncologist. 2014;19:350-1.

18. Adam R, Aloia T, Lévi F, Wicherts DA, de Haas RJ, Paule B, et al. Hepatic resection after rescue cetuximab treatment for colorectal liver metastases previously refractory to conventional systemic therapy. J Clin Oncol. 2007;25:4593-602.

19. Poston GP, Adam R, Alberts S, Curley S, Figueras J, Haller D, et al. OncoSurge: a strategy for improving resectability with curative intent in metastatic colorectal cancer. J Clin Oncol. 2005;23:7125-34.

20. Adam R, Wicherts DA, de Haas RJ, Ciacio O, Lévi F, Paule B, et al. Patients with initially unresectable colorectal liver metastases: is there a possibility of cure? J Clin Oncol. 2009;27:1829-35.

21. Yoshida K, Yamaguchi K, Okumura N, Osada S, Takahashi T, Tanaka Y, et al. The roles of surgical oncologists in the new era-minimally invasive surgery for early gastric cancer and adjuvant surgery for metastatic gastric cancer. Pathobiology. 2011;78:343-52.

22. Suzuki T, Tanabe K, Taomoto J, Yamamoto H, Tokumoto N, Yoshida K, et al. Preliminary trial of adjuvant surgery for advanced gastric cancer. Oncol Lett. 2010;1:743-7.

23. Satoh S, Okabe H, Teramukai S, Hasegawa S, Ozaki N, Ueda S, et al. Phase II trial of combined treatment consisting of preoperative $\mathrm{S}-1$ plus cisplatin followed by gastrectomy and postoperative S-1 for stage IV gastric cancer. Gastric Cancer. 2012;15:61-9.

24. Han DS, Suh YS, Kong SH, Lee HJ, Im SA, Bang YJ, et al. Outcomes of surgery aiming at curative resection in good responder to induction chemotherapy for gastric cancer with distant metastases. J Surg Oncol. 2013;107:511-6.

25. Okabe H, Ueda S, Obama K, Hosogi H, Sakai Y. Induction chemotherapy with S-1 plus cisplatin followed by surgery for treatment of gastric cancer with peritoneal dissemination. Ann Surg Oncol. 2009;16:3227-36.

26. Satoh S, Hasegawa S, Ozaki N, Okabe H, Watanabe G, Nagayama $\mathrm{S}$, et al. Retrospective analysis of 45 consecutive patients with advanced gastric cancer treated with neoadjuvant chemotherapy using an S-1/CDDP combination. Gastric Cancer. 2006;9:129-35.

27. Japanese Gastric Cancer Association: Japanese Guideline for Gastric Carcinoma. In: Sano T, editor. Kanehara-shuppan; 2014.

28. Takashima A, Boku N, Kato K, Nakamura K, Mizusawa J, Fukuda $\mathrm{H}$, et al. Survival prolongation after treatment failure of 
first-line chemotherapy in patients with advanced gastric cancer: combined analysis of the Japan Clinical Oncology group trials JCOG9205 and JCOG9912. Gastric Cancer. 2014;17:522-8.

29. Narahara H, Iishi H, Imamura H, Tsuburaya A, Chin K, Imamoto $\mathrm{H}$, et al. Randomized phase III study comparing the efficacy and safety of irinotecan plus S-1 with S-1 alone as first-line treatment for advanced gastric cancer (study GC0301/TOP-002). Gastric Cancer. 2011;14:72-80.

30. Ryu MH, Baba E, Lee KH, Boku N, Park YI, Hyodo I, et al. Phase III trial of a 3-weekly versus 5-weekly schedule of S-1 plus cisplatin (SP) combination chemotherapy for first-line treatment of advanced gastric cancer (AGC): SOS study. J Clin Oncol. 2013;31:LBA4024.

31. Yamada Y, Higuchi K, Nishikawa K, Gotoh M, Fuse N, Sugimoto N, et al. Phase III study comparing oxaliplatin plus S-1 with cisplatin plus $\mathrm{S}-1$ in chemotherapy-naïve patients with advanced gastric cancer. Ann Oncol. 2014; doi:10.1093/annonc/mdu472.

32. Ohtsu A, Shah MA, Van Cutsem E, Rha SY, Sawaki A, Park SR, et al. Bevacizumab in combination with chemotherapy as firstline therapy in advanced gastric cancer: a randomized, doubleblind, placebo-controlled phase III study. J Clin Oncol. 2011;29:3968-76.

33. Yamaguchi K, Sawaki A, Doi T, Satoh T, Yamada Y, Omuro Y, et al. Efficacy and safety of capecitabine plus cisplatin in Japanese patients with advanced or metastatic gastric cancer: subset analyses of the AVAGAST study and the ToGA study. Gastric Cancer. 2013;6:175-82.

34. Katayama H, Ito S, Sano T, Takahari D, Mizusawa J, Boku N, et al. Stomach Cancer Study Group of the Japan Clinical Oncology Group. A phase II study of systemic chemotherapy with docetaxel, cisplatin, and S-1 (DCS) followed by surgery in gastric cancer patients with extensive lymph node metastasis: Japan Clinical Oncology Group study JCOG1002. Jpn J Clin Oncol. 2012;42:556-9.

35. Sato Y, Takayama T, Sagawa T, Takahashi Y, Ohnuma H, Okubo $\mathrm{S}$, et al. Phase II study of S-1, docetaxel and cisplatin combination chemotherapy in patients with unresectable metastatic gastric cancer. Cancer Chemother Pharmacol. 2010;66:721-8.

36. Murad AM, Santiago FF, Petroianu A, Rocha PR, Rodrigues MA, Rausch M. Modified therapy with 5-fluorouracil, doxorubicin, and methotrexate in advanced gastric cancer. Cancer. 1993;72:37-41

37. Vanhoefer U, Rougier P, Wilke H, Ducreux MP, Lacave AJ, Van Cutsem E, et al. Final results of a randomized phase III trial of sequential high-dose methotrexate, fluorouracil, and doxorubicin versus etoposide, leucovorin, and fluorouracil versus infusional fluorouracil and cisplatin in advanced gastric cancer: a trial of the European Organization for Research and Treatment of Cancer Gastrointestinal Tract Cancer Cooperative Group. J Clin Oncol. 2000;18:2648-57.

38. Ajani JA, Buyse M, Lichinitser M, Gorbunova V, Bodoky G, Douillard JY, et al. Combination of cisplatin/S-1 in the treatment of patients with advanced gastric or gastroesophageal adenocarcinoma: results of noninferiority and safety analyses compared with cisplatin/5-fluorouracil in the First-Line Advanced Gastric Cancer Study. Eur J Cancer. 2013;49:3616-24.

39. Van Cutsem E, Moiseyenko VM, Tjulandin S, Majlis A, Constenla M, Boni C, et al. Phase III study of docetaxel and cisplatin plus fluorouracil compared with cisplatin and fluorouracil as firstline therapy for advanced gastric cancer: a report of the V325 Study Group. J Clin Oncol. 2006;24:4991-7.

40. Dank M, Zaluski J, Barone C, Valvere V, Yalcin S, Peschel C, et al. Randomized phase III study comparing irinotecan combined with 5-fluorouracil and folinic acid to cisplatin combined with 5-fluorouracil in chemotherapy naive patients with advanced adenocarcinoma of the stomach or esophagogastric junction. Ann Oncol. 2008;19:1450-7.

41. Cunningham D, Starling N, Rao S, Iveson T, Nicolson M, Coxon F, et al. Upper Gastrointestinal Clinical Studies Group of the National Cancer Research Institute of the United Kingdom. Capecitabine and oxaliplatin for advanced esophagogastric cancer. N Engl J Med. 2008;358:36-46.

42. Kang YK, Kang WK, Shin DB, Chen J, Xiong J, Wang J, et al. Capecitabine/cisplatin versus 5-fluorouracil/cisplatin as first-line therapy in patients with advanced gastric cancer: a randomised phase III noninferiority trial. Ann Oncol. 2009;20:666-73.

43. Van Cutsem E, de Haas S, Kang YK, Ohtsu A, Tebbutt NC, Ming $\mathrm{Xu} \mathrm{J}$, et al. Bevacizumab in combination with chemotherapy as first-line therapy in advanced gastric cancer: a biomarker evaluation from the AVAGAST randomized phase III trial. J Clin Oncol. 2012;30:2119-27.

44. Proserpio I, Rausei S, Barzaghi S, Frattini F, Galli F, Iovino D, et al. Multimodal treatment of gastric cancer. World J Gastrointest Surg. 2014;6:55-8.

45. Sun J, Song Y, Wang Z, Chen X, Gao P, Xu Y, et al. Clinical significance of palliative gastrectomy on the survival of patients with incurable advanced gastric cancer: a systematic review and meta-analysis. BMC Cancer. 2013;13:577.

46. Dittmar Y, Rauchfuss F, Goetz M, Jandt K, Scheuerlein H, Heise $\mathrm{M}$, et al. Non-curative gastric resection for patients with stage 4 gastric cancer-a single center experience and current review of literature. Langenbecks Arch Surg. 2012;397:745-53.

47. Mahar A, Coburn N, Karanicolas P, Viola R, Helyer L. Effective palliation and quality of life outcomes in studies of surgery for advanced, non-curative gastric cancer: a systematic review. Gastric Cancer. 2012;15(Suppl 1):S138-45.

48. Pavlidis TE, Pavlidis ET. Role of stenting in the palliation of gastroesophageal junction cancer: a brief review. World J Gastrointest Surg. 2014;6:38-41.

49. Lee HO, Lee JJ. Nutritional intervention using nutrition care process in a malnourished patient with chemotherapy side effects. Clin Nutr Res. 2015;4:63-7.

50. Fujitani K, Yang HK, Kurokawa Y, Park do J, Tsujinaka T, Park $\mathrm{BJ}$, et al. Randomized controlled trial comparing gastrectomy plus chemotherapy with chemotherapy alone in advanced gastric cancer with a single non-curable factor: Japan Clinical Oncology Group Study JCOG 0705 and Korea Gastric Cancer Association Study KGCA01. Jpn J Clin Oncol. 2008;38(7):504-6.

51. Shimada H, Okazumi S, Koyama M, Murakami K. Japanese Gastric Cancer Association Task Force for Research Promotion: clinical utility of $18 \mathrm{~F}$-fluoro-2-deoxyglucose positron emission tomography in gastric cancer. A systematic review of the literature. Gastric Cancer. 2011;14:13-21.

52. Shimada H, Noie T, Ohashi M, Oba K, Takahashi Y. Clinical significance of serum tumor markers for gastric cancer: a systematic review of literature by the Task Force of the Japanese Gastric Cancer Association. Gastric Cancer. 2014;17:26-33.

53. Van Cutsem E, Cervantes A, Nordlinger B, Arnold D, ESMO Guidelines Working Group. Metastatic colorectal cancer: ESMO Clinical Practice Guidelines for diagnosis, treatment and followup. Ann Oncol. 2014;25(Suppl 3):iii1-9.

54. Folprecht G, Gruenberger T, Bechstein W, Raab HR, Weitz J, Lordick F, et al. Survival of patients with initially unresectable colorectal liver metastases treated with FOLFOX/cetuximab or FOLFIRI/cetuximab in a multidisciplinary concept (CELIM study). Ann Oncol. 2014;25:1018-25.

55. Kodera Y, Ito S, Mochizuki Y, Ohashi N, Tanaka C, Kobayashi $\mathrm{D}$, et al. Long-term follow up of patients who were positive for peritoneal lavage cytology: final report from the CCOG0301 study. Gastric Cancer. 2012;15:335-7. 
56. Takemura N, Saiura A, Koga R, Arita J, Yoshioka R, Ono Y, et al. Long-term outcomes after surgical resection for gastric cancer liver metastasis: an analysis of 64 macroscopically complete resections. Langenbecks Arch Surg. 2012;397:951-7.

57. Kodera Y, Fujitani K, Fukushima N, Ito S, Muro K, Ohashi N, et al. Surgical resection of hepatic metastasis from gastric cancer: a review and new recommendation in the Japanese gastric cancer treatment guidelines. Gastric Cancer. 2014;17:206-12.

58. Qiu J-L, Deng M-G, Li W, Zou R-H, Li B-K, Zheng Y, et al. Hepatic resection for synchronous hepatic metastasis from gastric cancer. EJSO. 2013;39:694-700.

59. Oki E, Tokunaga S, Emi Y, Kusumoto T, Yamamoto M, Fukuzawa K, et al. Surgical treatment of liver metastasis of gastric cancer: a retrospective multicenter cohort study (KSCC1302). Gastric Cancer. 2015. doi:10.1007/s10120-015-0530-z.

60. Kodera Y, Kobayashi D, Chie Tanaka C, Fujiwara M. Gastric adenocarcinoma with para-aortic lymph node metastasis: a borderline resectable cancer ? Surg Today. 2015;45:1082-90.

61. Matsumoto T, Sasako M, Mizusawa J, Hirota S, Ochiai A, Kushima R, et al. HER2 expression in locally advanced gastric cancer with extensive lymph node (bulky N2 or paraaortic) metastasis (JCOG1005-A trial). Gastric Cancer. Published online: 04 July 2014.

62. Tsuburaya A, Mizusawa J, Tanaka Y, Fukushima N, Nashimoto A, Sasako M. Neoadjuvant chemotherapy with S-1 and cisplatin followed by D2 gastrectomy with para-aortic lymph node dissection for gastric cancer with extensive lymph node metastasis. BJS. 2014;101:653-60.

63. Iwasaki Y, Sasako M, Yamamoto S, Nakamura K, Sano T, Katai $\mathrm{H}$, et al. Phase II study of preoperative chemotherapy with S-1 and cisplatin followed by gastrectomy for clinically resectable type 4 and large type 3 gastric cancers (JCOG0210). J Surg Oncol. 2013;107:741-5.

64. Inoue T, Yachida S, Usuki H, Kimura T, Hagiike M, Okano K, et al. Pilot feasibility study of neoadjuvant chemoradiotherapy with S-1 in patients with locally advanced gastric cancer featuring adjacent tissue invasion or JGCA bulky N2 lymph node metastases. Ann Surg Oncol. 2012;19:2937-45.

65. Liao Y, Yang Z-L, Peng J-S, Xiang J, Wang J-P. Neoadjuvant chemotherapy for gastric cancer: a meta-analysis of randomized, controlled trials. J Gastroenterol Hepatol. 2013;28:777-82.

66. Fujitani K. Overview of adjuvant and neoadjuvant therapy for resectable gastric cancer in the east. Dig Surg. 2013;30:119-29.

67. Tsuburaya A, Nagata N, Cho H, Hirabayashi N, Kobayashi M, Kojima $\mathrm{H}$, et al. Phase II trial of paclitaxel and cisplatin as neoadjuvant chemotherapy for locally advanced gastric cancer. Cancer Chemother Pharmacol. 2013;71:1309-14.

68. Fujitani K, Mano M, Hirao M, Kodama Y, Tsujinaka T. Posttherapy nodal status, not graded histologic response, predicts survival after neoadjuvant chemotherapy for advanced gastric cancer. Ann Surg Oncol. 2012;19:1936-43.

69. Lorenzen S, Panzram B, Rosenberg R, Nekarda H, Becker K, Schenk U, et al. Prognostic significance of free peritoneal tumor cells in the peritoneal cavity before and after neoadjuvant chemotherapy in patients with gastric carcinoma undergoing potentially curative resection. Ann Surg Oncol. 2010;17:2733-9.

70. Yamaguchi H, Kitayama J, Ishigami H, Emoto S, Yamashita H, Watanabe T. A phase 2 trial of intravenous and intraperitoneal paclitaxel combined with S-1 for treatment of gastric cancer with macroscopic peritoneal metastasis. Cancer. 2013;119:3354-8.

71. Coccolini F, Cotte E, Glehen O, Lotti M, Poiasina E, Catena F, et al. Intraperitoneal chemotherapy in advanced gastric cancer. Meta-analysis of randomized trials. EJSO. 2014;40:12-26.
72. Schwarz R. Redefining surgery for gastric cancer: is "stage-appropriate surgery" an appropriate standard for Western surgeons? Gastric Cancer. 2000;3:116-8.

73. Mezhir JJ, Shah MA, Jacks LM, Brennan MF, Coit DG, Strong VE. Positive peritoneal cytology in patients with gastric cancer: natural history and outcome of 291 patients. Ann Surg Oncol. 2010;17:3173-80.

74. Rudloff U, Langan RC, Mullinax JE, Beane JD, Steinberg SM, Beresnev T, et al. Impact of maximal cytoreductive surgery plus regional heated intraperitoneal chemotherapy (HIPEC) on outcome of patients with peritoneal carcinomatosis of gastric origin: results of the GYMSSA trial. J Surg Oncol. 2014;110:275-84.

75. Oshiro Y, Takahashi K, Sasaki R, Kondo T, Sakashita S, Ohkohchi N. Adjuvant surgery for advanced extrahepatic cholangiocarcinoma. World J Gastroenterol. 2013;19:6934-8.

76. Jones RP, Hamann S, Malik HZ, Fenwick SW, Poston GJ, Folprecht G. Defined criteria for resectability improves rates of secondary resection after systemic therapy for liver limited metastatic colorectal cancer. Eur J Cancer. 2014;50:1590-601.

77. Makuuchi H, editor. The Japan Esophageal Society: Japanese guideline for diagnosis and treatment for esophageal cancer. Tokyo, Kanehara Shuppan; 2007. p. 70-1.

78. Nakamura T, Hyashi K, Ota M, Eguchi R, Ide H, Takasaki K, et al. Salvage esophagectomy after definitive chemotherapy and radiotherapy for advanced esophageal cancer. Am J Surg. 2004;188:161-6.

79. Wada Y, Yoshida K, Hihara J, Taomoto J, Suzuki T, Mizuiri H, et al. A specific neutrophil elastase inhibitor, sivelestat, suppresses the growth of gastric carcinoma cells by preventing the release of TGF- $\alpha$. Cancer Sci. 2006;97:1037-43.

80. Wada Y, Yoshida K, Tsutani Y, Shigematsu H, Oeda M, Suzuki $\mathrm{T}$, et al. Neutrophil elastase induces cell proliferation and migration by the release of TGF- $\alpha$, PDGF and VEGF in esophageal cell lines. Oncol Rep. 2007;17:161-7.

81. Bauer S, Hartmann JT, de Wit M, Lang H, Grabellus F, Antoch $\mathrm{G}$, et al. Resection of residual disease in patients with metastatic gastrointestinal stromal tumors responding to treatment with imatinib. Int J Cancer. 2005;117:316-25.

82. Raut CP, Posner M, Desai J, Morgan JA, George S, Zahrieh D, et al. Surgical management of advanced gastrointestinal stromal tumors after treatment with targeted systemic therapy using kinase inhibitor. J Clin Oncol. 2006;24:2325-31.

83. Yoshikawa T, Tanabe K, Nishikawa K, Ito Y, Matsui T, Kimura $\mathrm{Y}$, et al. Induction of a pathological complete response by four courses of neoadjuvant chemotherapy for gastric cancer: early results of the randomized phase II COMPASS trial. Ann Surg Oncol. 2014;21:213-9.

84. Gronchi A, Fiore M, Miselli F, Lagonigro MS, Coco P, Messina A, et al. Surgery of residual disease following molecular-targeted therapy with imatinib mesylate in advanced/metastatic GIST. Ann Surg. 2007;245:341-6.

85. Rutkowski P, Nowecki Z, Nyckowski P, Dziewirski W, Grzesiakowska U, Nasierowska-Guttmejer A, et al. Surgical treatment of patients with initially inoperavle and/or metastatic gastrointestinal stromal tumors (GIST) during therapy with imatinib mesylate. J Surg Oncol. 2006;93:304-11.

86. Bauer S, Rutkowski P, Hohenberger P, Miceli R, Fumagalli E, Siedlecki JA, et al. Long-term follow-up of patients with GIST undergoing metastasectomy in the era of imatinib-analysis of prognostic factors (EORTC-STBSG collaborative study). Eur J Surg Oncol. 2014;40:412-9. 